
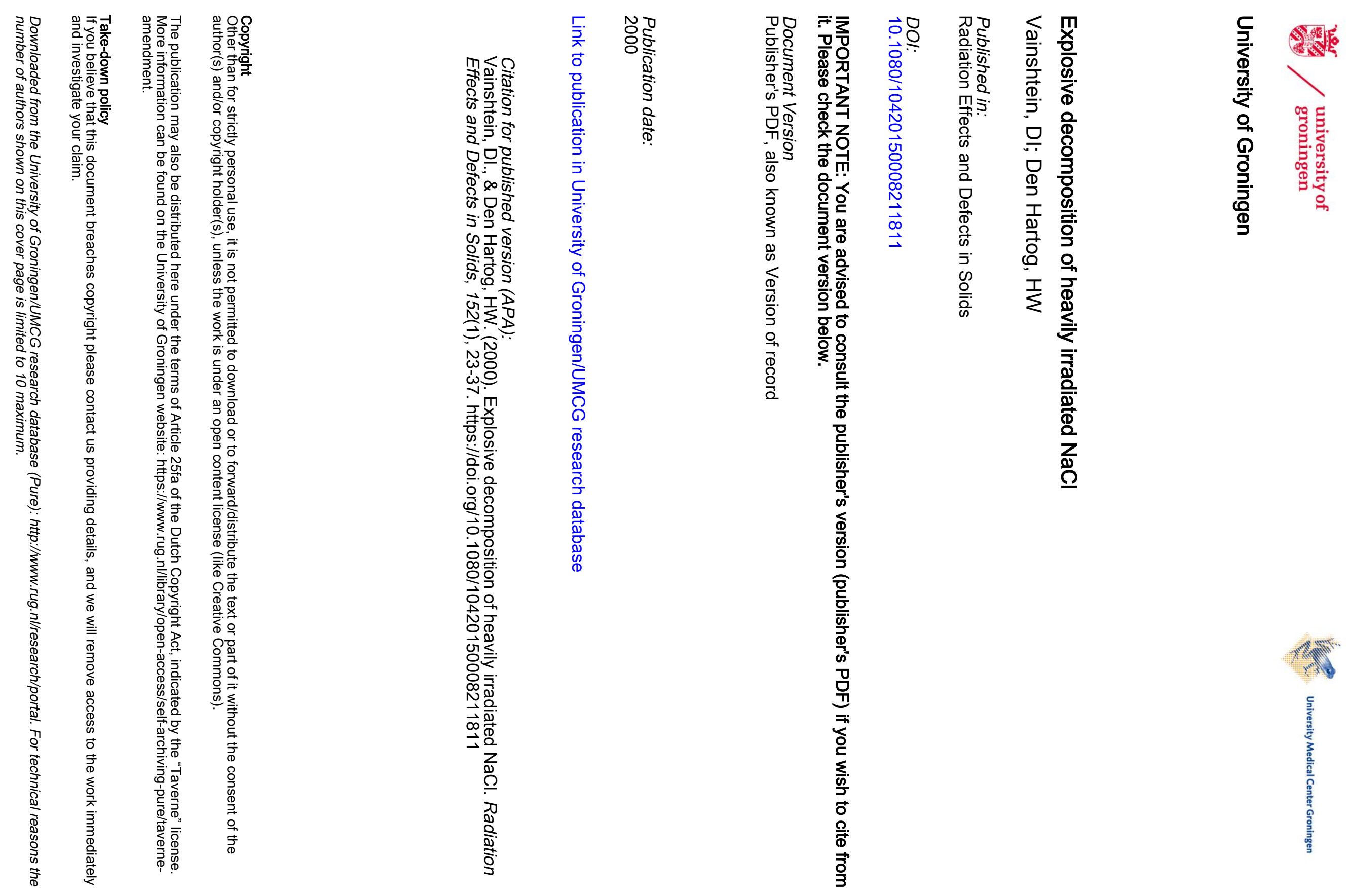


\title{
EXPLOSIVE DECOMPOSITION OF HEAVILY IRRADIATED NaCl
}

\author{
D.I. VAINSHTEIN and H.W. DEN HARTOG* \\ Solid State Physics Laboratory, University of Groningen, \\ Nijenborgh 4, 9747 AG Groningen, The Netherlands
}

(Received I February 1999; In final form 4 February 1999)

\begin{abstract}
In heavily irradiated $\mathrm{NaCl}$ explosions can be initiated during irradiation or later, after the irradiation, when the samples are heated to temperatures in the range $100-250^{\circ} \mathrm{C}$. As a result of the irradiation $\mathrm{Na}$ and $\mathrm{Cl}_{2}$ precipitates, dislocations and voids are produced, along with stored energy (the maximum value observed until now $\sim 76 \mathrm{~kJ} / \mathrm{mol}$, which is about $18.5 \%$ of the enthalpy of formation of $\mathrm{NaCl}, 411.2 \mathrm{~kJ} / \mathrm{mol}$ ). This implies that heavily irradiated $\mathrm{NaCl}$ is a highly energetic material. We have observed that the samples, which revealed large radiation-induced voids, explode rather easily. In these samples the instability connected with large voids (hot spots) probably initiates the explosive release of stored energy, which is in many cases accompanied by characteristic (explosive) sounds. In this paper we will discuss the nature of the explosions and show that a basically stable insulating compound, such as $\mathrm{NaCl}$, may become unstable after heavy irradiation.
\end{abstract}

Keywords: Sodium chloride; Electrons; Irradiation; Decomposition; Explosion; DSC (differential scanning calorimetry)

\section{INTRODUCTION}

There is considerable scientific interest in hot spots, shock wave initiation, detonation and explosive decomposition of inhomogeneous solids [1-4]. No information is available yet about explosive decomposition of solids, which become unstable during exposure to ionizing irradiation. In 1958 Bowden and Yoffe [5] stated that they had investigated many materials and found that even explosives do not explode due to irradiation, but 25 years later Miles et al. [6] observed experimentally that

* Corresponding author. 
the sensitivity of the well known explosive material HMX is enhanced by relatively small doses of ionizing radiation (e.g. $7.5 \mathrm{Mrad}$ ), while an irradiation dose of $10 \mathrm{Mrad}$ led to spontaneous explosions. We will show for the first time that also a stable solid such as $\mathrm{NaCl}$ may decompose after exposure to heavy irradiation (for doses $>15 \mathrm{Grad}$ ).

In particular, we will show that the observed decomposition is not associated with the expansion of gas in radiation induced chlorine bubbles. The proof for this proposition is very simple and quite straight forward, as we will see in the presentation of the experimental results. If the decomposition is due to the expansion of the gas in the chlorine bubbles, the sample weight should be reduced, because chlorine gas will escape from the sample during the decomposition process. In contrast with this we have observed that the sample weight before and after decomposition is the same. In fact, the most characteristic feature of the explosive decomposition is a fast chemical reaction taking place during the spike, which is in contradiction with decomposition induced by the expansion of chlorine gas.

Campbell et al. [4] showed that shock waves in explosives do not travel as an inert shock, but as a shock to which the explosive contributes energy from reaction at voids and defects. This has been a very important observation for the development of models for the initiation of explosive solids. Campbell et al. [4] achieved initiation by exposing their samples to shock waves and it appeared that the resulting shock waves traveling within the explosives were rough, which means that in the inhomogeneous material there are small regions of convergence, where exothermal reactions may occur. From this important feature of these materials, the ideas about shock initiation of explosives emerge. Hot spots play an essential role, because in energetic materials with exothermal reactions they may stimulate the release of energy of reaction at considerable distances from the hot spot by generating highly energetic shock waves. More recently, Lee and Tarver [7] concluded that the build-up of energy in the shock wave may ultimately lead to decomposition. In order to achieve initiation and finally explosive decomposition, the exothermal reactions should be very fast. Reactions, which are controlled by diffusion processes do not contribute effectively to the explosive phenomena, because these reactions are too slow.

Our irradiated samples do not need shock waves from an external source to initiate the explosive decomposition, because they are initiated 
autocatalytically within the irradiated material by the instability of large, radiation-induced voids [8]. In several cases we have concluded that the explosions of the $\mathrm{NaCl}$ samples occurred during irradiation, because the most heavily damaged samples were completely shattered during the irradiation. For many heavily irradiated samples we have recorded the explosions with fast video techniques in conjunction with optical microscopy during heating in the temperature range between $100^{\circ} \mathrm{C}$ and $250^{\circ} \mathrm{C}$. We have found that there is a correlation between the void size and the stability of the irradiated samples. Samples with large voids were more likely to explode than samples with small voids. In addition, we have found that samples with large voids exploded at lower temperatures than samples with smaller voids.

\section{EXPERIMENTAL RESULTS AND DISCUSSION}

In Fig. 1 we show the result of a scanning electron microscopy (SEM) experiment on $\mathrm{NaCl}: \mathrm{K}$, which had been irradiated at $100^{\circ} \mathrm{C}$ (dose $150 \mathrm{Grad}$, dose rate $100 \mathrm{Mrad} / \mathrm{h}$ ). This is a very heavily damaged sample in which about $8 \%$ of the $\mathrm{NaCl}$ molecules was transformed into $\mathrm{Na}$ and chlorine. The black regions are voids, which are intersected by the cleavage plane. The small light spots at the surface are irregularities, which are formed when the sample is exposed to air. Possibly, these
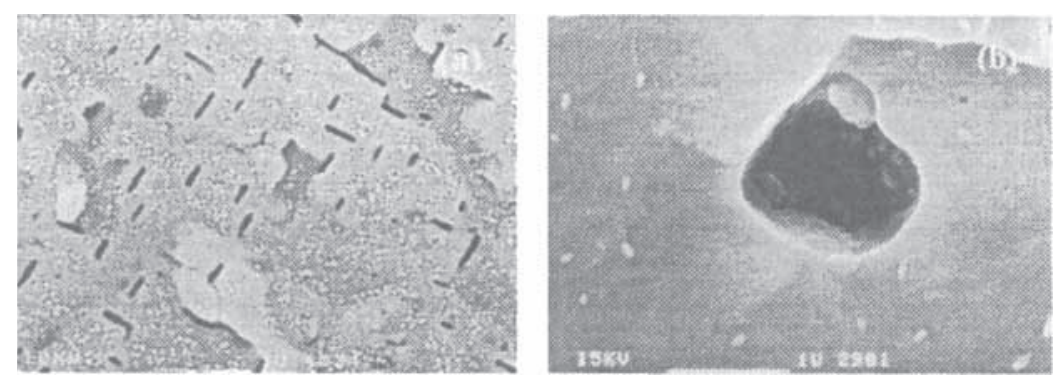

FIGURE 1 Picture (a), SEM picture of irradiated $\mathrm{NaCl}: 0.1 \mathrm{~mol} \% \mathrm{KCl}$ (dose $150 \mathrm{Grad}$, dose rate $100 \mathrm{Mrad} / \mathrm{h}$ ), with voids along the crystallographic $\langle 100\rangle$ directions. Picture (b), a very large void in the same irradiated $\mathrm{NaCl}$ sample. This large void is unstable and may give rise to a hot spot, which is capable to initiate explosive decomposition. The length of the bar at the bottom of pictures 1 (a) and (b) is $1 \mu \mathrm{m}$. The concentration of metallic $\mathrm{Na}$ in this sample, determined from the latent heat of melting, is 8 at $\%$. 
spots are due to products formed at the surface due to the reaction between $\mathrm{Na}$ colloids and water vapor or colloids and oxygen. We have observed, that the number and size of the light spots increase with increasing time of exposure of the surface to air. The size of the voids in the present sample is typically a few tenths to $0.5 \mu \mathrm{m}$ (Fig. 1(a)), but in some other regions within the same sample we have also found sometimes voids larger than $1 \mu \mathrm{m}$ (see Fig. 1(b))!

The result in Fig. 1 is just one example of many observations, which have been made in our laboratory. In the early stages of void formation, the voids are usually very small and more or less round. With increasing dose or with increasing amount of damage the voids become more and more elongated along the crystallographic $\langle 100\rangle$ directions. In Fig. 2 we show the voids, as observed in SEM experiments, for different stages of the damage formation and the above mentioned trends can be seen
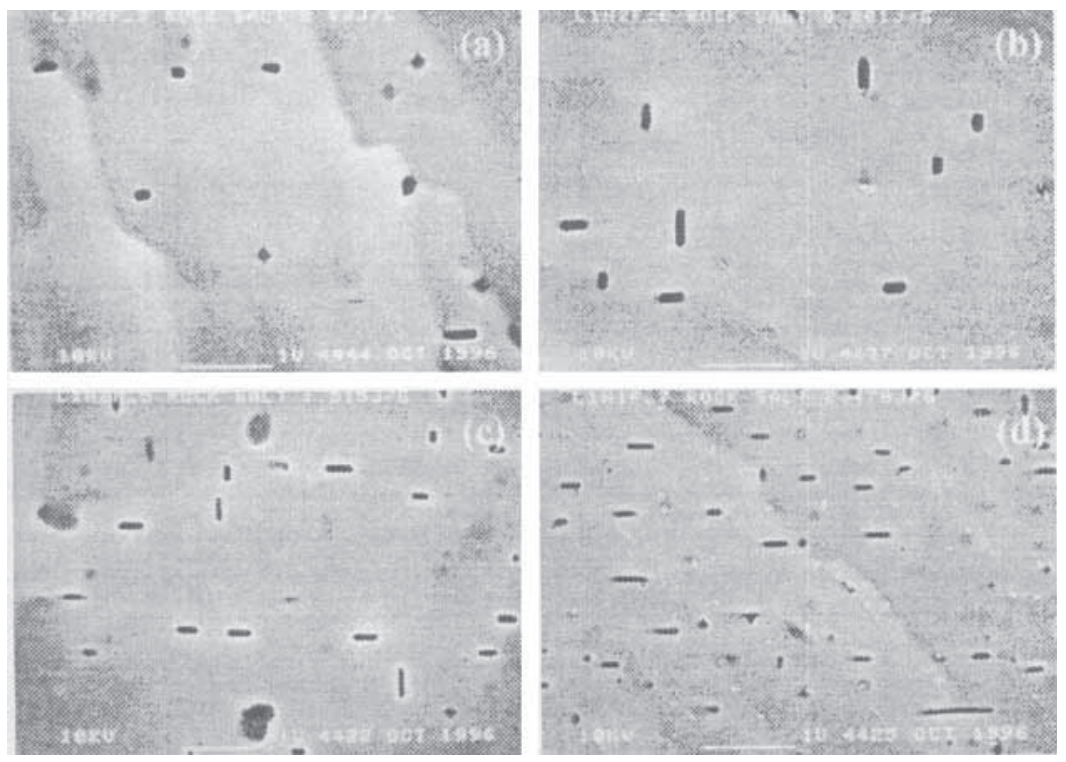

FIGURE 2 The development of voids in irradiated natural rock salt. For small damage levels the voids are small and have a more or less round shape. With increasing damage levels the average size of the voids grow. In addition, with increasing amount of damage the voids become increasingly elongated. The damage level of the samples can be deduced from the latent heat of melting (in $\mathrm{J} / \mathrm{g}$ ), given at the top of each of the individual pictures. A latent heat of melting of about $0.45 \mathrm{~J} / \mathrm{g}$ corresponds to 1 at $\%$ metallic $\mathrm{Na}$ in the sample. 
very clearly. It should be noted that apart from the voids displayed in Figs. 1 and 2 we have observed $\mathrm{Na}$ and $\mathrm{Cl}_{2}$ precipitates, which were present in several extreme cases in overwhelming concentrations (up to more than 15 at \%). These concentrations of $\mathrm{Na}$ and $\mathrm{Cl}_{2}$ have been measured by means of differential scanning calorimetry (DSC) experiments, which allowed us to determine the latent heat of melting of the radiation-induced $\mathrm{Na}$ and $\mathrm{Cl}_{2}$ precipitates. In agreement with the above-mentioned percentages the amount of radiation induced stored energy in these materials is often very large (e.g. $1.3 \mathrm{MJ} / \mathrm{kg}$ ).

It is assumed that a minimum void size of about $0.5-1 \mu \mathrm{m}$ is required for the resulting hot spot to grow [2,3]. Khasainov et al [9] have reported about the relatively high sensitivity of high explosives (HE) containing $0.1-10 \mu \mathrm{m}$ voids. The number and size of the voids in irradiated $\mathrm{NaCl}$ depend upon the irradiation temperature the dose and the presence of dopants. $\mathrm{NaCl}: 0.1 \mathrm{~mol} \% \mathrm{KCl}$ shows extensive void formation, whereas in pure $\mathrm{NaCl}$ samples or samples with $\mathrm{LiCl}$, or $\mathrm{KBF}_{4}$ there are only relatively small voids. $\mathrm{NaCl}: \mathrm{KCl}$ often showed explosive decomposition well below $200^{\circ} \mathrm{C}$, whereas materials with only small voids did not decompose very easily or exploded at higher temperatures (up to $250^{\circ} \mathrm{C}$ ).

Hot spots in explosives are often created by the presence of voids $[1-4]$. An early model of hot spot formation has been presented by Seely [10] and it has been developed further by Stresau and Kennedy [11]. Later another model was developed, using the amount of plastic work done at the void peripheries by the dynamic collapse of voids $[12,13]$. Both models involve a highly localized and fast release of energy at the void. Recently, by applying high speed computers, several authors have simulated collapsing voids in explosives [2,14-16], which has led to significant improvements in our understanding of the processes in energetic materials. Of course we do not know yet, if in irradiated $\mathrm{NaCl}$ the initiation is caused exactly in the same way by the collapse of voids in high explosives. However, we have strong evidence that voids play a significant role in the initiation of heavily irradiated $\mathrm{NaCl}$.

SEM results of heavily irradiated (doped) $\mathrm{NaCl}$ often show many voids. In addition, these samples contain considerable amounts of stored energy (SE). During irradiation $\mathrm{Na}^{+}$and $\mathrm{Cl}^{-}$ions of the $\mathrm{NaCl}$ lattice are transformed into $\mathrm{Na}$ precipitates (colloids) and $\mathrm{Cl}_{2}$ precipitates. In Fig. 3 we show the result of a DSC experiment revealing the 
endothermic latent heat $(\mathrm{LH})$ peaks of melting of $\mathrm{Na}\left(\right.$ at $\left.100^{\circ} \mathrm{C}\right)$ and $\mathrm{Cl}_{2}$ (at $-100^{\circ} \mathrm{C}$ ). Figure 3 also shows an exothermal peak due to the release of $\mathrm{SE}$ of back reactions between sodium and $\mathrm{Cl}_{2}$. In general, there is a linear relationship between the intensity of the melting peaks of $\mathrm{Na}$ and $\mathrm{Cl}_{2}$ on one hand and the SE peak on the other hand. This implies that LH measurements provide us with a quick, non-destructive check on the $\mathrm{SE}$ in irradiated $\mathrm{NaCl}$. From our $\mathrm{LH}$ results we have calculated for several samples $S E$ values as large as $1.3 \mathrm{MJ} / \mathrm{kg}$, which is equal to $18.5 \%$ of the enthalpy of formation of $\mathrm{NaCl}$ ! We are convinced that even higher SE values can be obtained by increasing the dose, because in many cases we did not observe any sign of saturation of the SE as a function of the dose.

The DSC experiments of several irradiated $\mathrm{NaCl}$ crystals revealed, apart from the above mentioned melting peaks, and the SE peak shown in Fig. 3 many sharp spikes between $120^{\circ} \mathrm{C}$ and $250^{\circ} \mathrm{C}$. These spikes are indicative for fast and spontaneous (explosive) processes taking place.

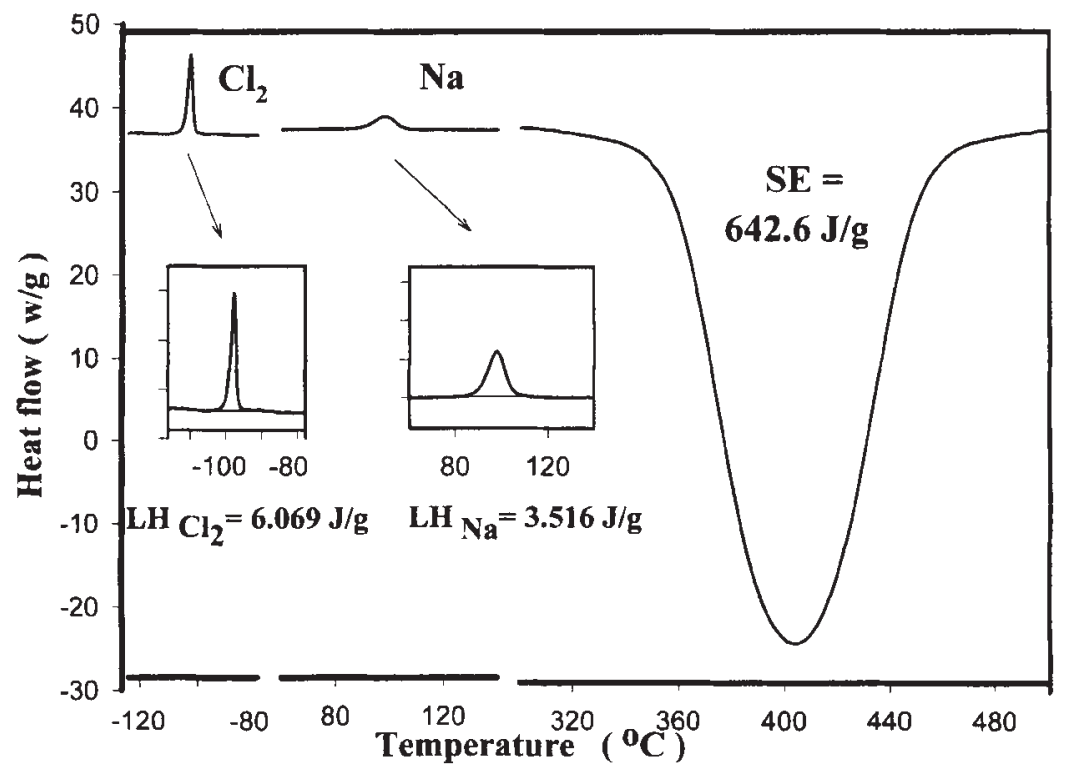

FIGURE 3 DSC scan of $\mathrm{NaCl}: 0.1 \mathrm{~mol} \% \mathrm{KCl}$ (weight $9.31 \mathrm{mg}$ ), showing the $\mathrm{LH}$ peaks of chlorine $\left(-100^{\circ} \mathrm{C}\right)$ and $\mathrm{Na}\left(100^{\circ} \mathrm{C}\right)$, and the SE peak at $400^{\circ} \mathrm{C}$. The $\mathrm{LH}$ and SE have been indicated. 


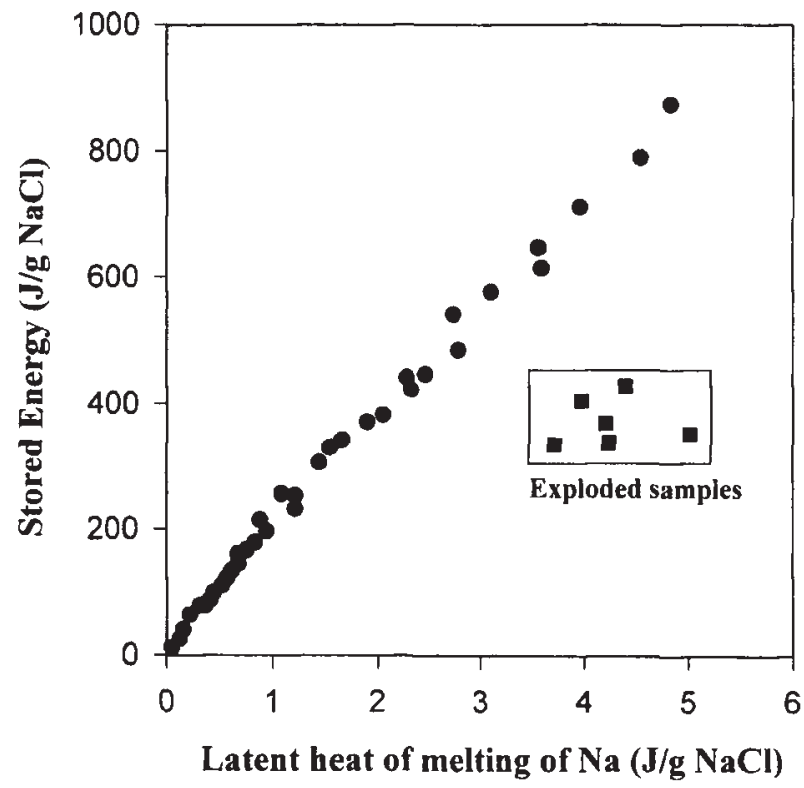

FIGURE 4 Combined $\mathrm{LH}$ and SE results of irradiated $\mathrm{NaCl}$. For the exploded samples the SE is $30-50 \%$ lower than expected.

For those experiments, where we have observed "DSC-spikes", we have observed discrepancies between the measured SE and the value expected on the basis of the LH results. Often the SE was $30-50 \%$ too low. In Fig. 4 we have plotted the SE as a function of the $\mathrm{LH}$, showing that exploded samples yield far too low values for the SE. After observing the thermal spikes the sample was completely shattered into many fragments. Some of these fragments are relatively large, but many of them are extremely small and have a dust-like appearance.

A typical result of a SEM experiment for a sample, which showed a thermal spike during heating, has been presented in Fig. 5. We note that prior to the spike the sample as a whole was glued onto the bottom of an aluminum pan, in order to avoid that the sample would be blown away completely. We can see from Fig. 5 that there are a few rather large fragments and many very fine ones. The large fragments will decompose during further heating, when new hot spots are created, because after heating to high temperatures the sample is transformed completely into a collection of extremely small, dust-like fragments. 


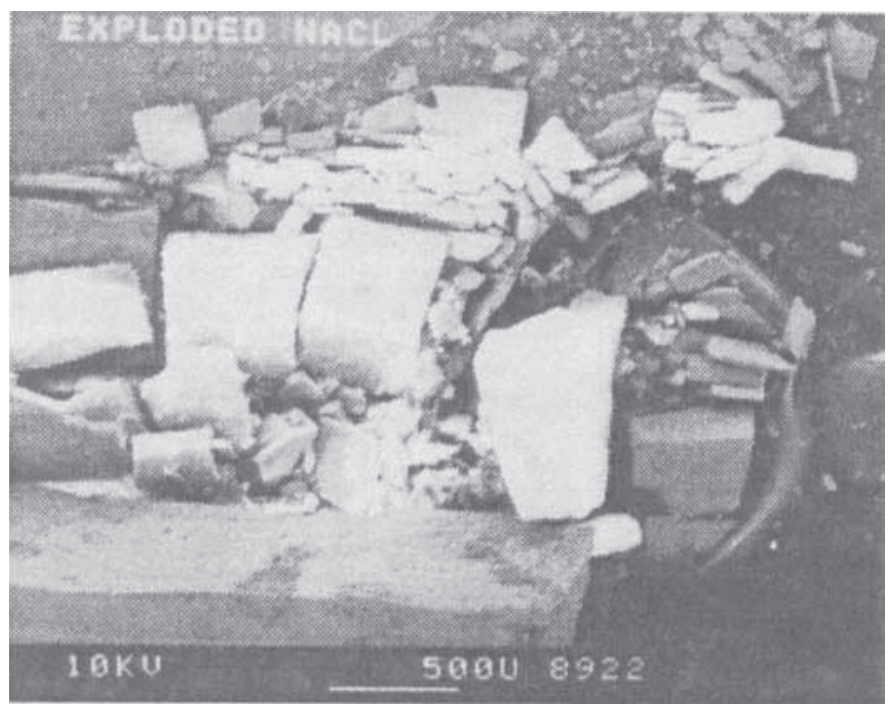

FIGURE 5 SEM result of an exploded sample. The sample was glued onto the bottom of an Al pan prior to the heating experiment, which induced the explosion slightly below $200^{\circ} \mathrm{C}$. The picture reveals the presence of large fragments and fine dust-like particles.

In several heating experiments on heavily damaged samples in our DSC-7 instrument the Pt cover, which is much heavier than the $\mathrm{NaCl}$ sample and is used to isolate the sample thermally from the remaining parts of the DSC setup, was blown away. These observations are indicative for violent reactions taking place in the samples during the thermal/DSC-spikes.

Our results presented in Fig. 4 show that during the spikes, occurring between the melting peak of $\mathrm{Na}$ and the peak associated with the stored energy, $30-50 \%$ of the $\mathrm{SE}$ is released. In order to pin-point the moment when the SE is released more accurately, we consider a DSC experiment on a sample of the type $\mathrm{NaCl}: 0.1 \mathrm{~mol} \% \mathrm{KCl}$ from room temperature exactly until the moment when the first thermal spike appears. We observe a melting peak due to Na-colloids (LH $5.312 \mathrm{~J} / \mathrm{g}$ ) and the first DSC-spike at $189^{\circ} \mathrm{C}$ (Fig. 6, curve a). Immediately after the appearance of the spike the temperature is lowered and a second run is carried out (Fig. 6, curve b). This DSC run shows a melting peak of $\mathrm{Na}$, which is $32 \%$ weaker than in the first run ( $\mathrm{LH} 3.636 \mathrm{~J} / \mathrm{g}$ ). In many other cases we have also observed spike-induced reductions of the latent heat peak up 


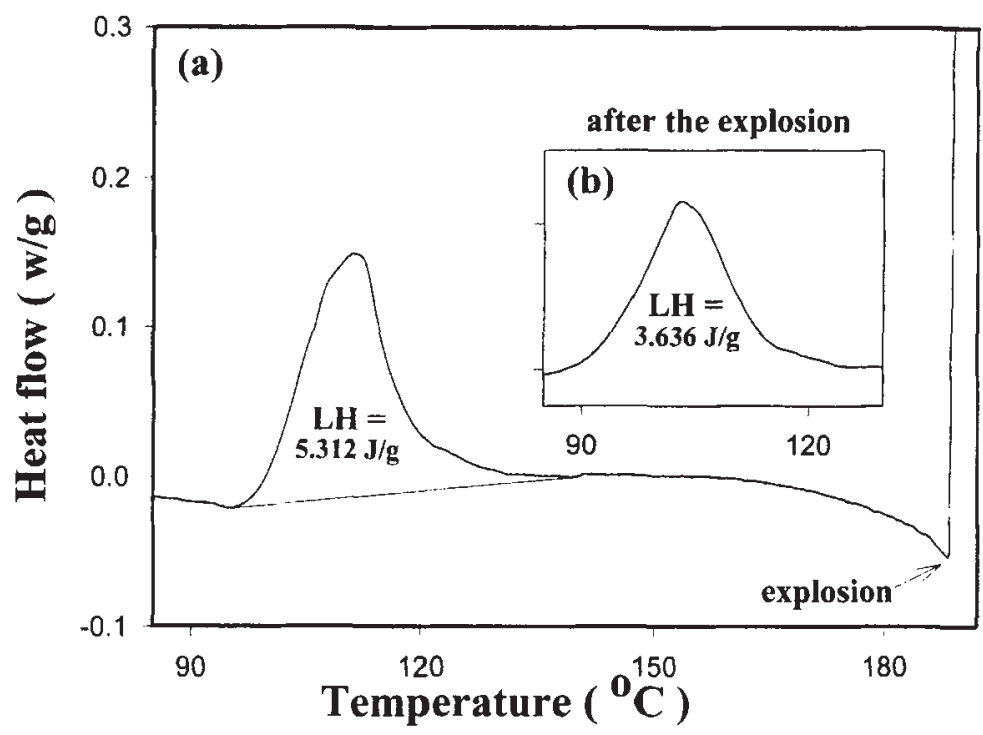

FIGURE 6 Curve (a), first DSC scan of irradiated $\mathrm{NaCl}: 0.1 \mathrm{~mol} \% \mathrm{KCl}$ (weight $10.32 \mathrm{mg}$ ), showing the $\mathrm{LH}$ peak at $100^{\circ} \mathrm{C}$ and the thermal spike at $189^{\circ} \mathrm{C}$; the $\mathrm{LH}$ of $\mathrm{Na}$ is $5.312 \mathrm{~J} / \mathrm{gr}$. Curve (b), second DSC scan of the same sample, with the same scale as curve (a). The LH has decreased by $32 \%$ due to the thermal spike.

to $30 \%$. We emphasize that these reductions were assigned to just one single spike.

We note that, before and after the experiment the sample weight was the same within experimental accuracy $(0.01 \mathrm{mg}$, or $0.1 \%)$. An important experimental fact is that similar samples, not showing thermal spikes due to explosions, did not show a decrease of the LH even if they were heated at $250^{\circ} \mathrm{C}$. In addition, we have found that heating the samples to temperatures very close but not including the spike, did not yield a reduction of the $\mathrm{LH}$ either. Usually, heating the same samples to temperatures high enough to pass the first thermal spike did yield loss of latent heat. This shows unambiguously that the LH decreases as a result of the very short DCS-spike. We have presented here only one example of many observations. Heavily irradiated $\mathrm{NaCl}: \mathrm{K}$ often decomposed between $160^{\circ} \mathrm{C}$ and $200^{\circ} \mathrm{C}$. Depending on the dopant, the dose and the irradiation temperature decompositions occurred up to about $250^{\circ} \mathrm{C}$. With increasing SE values the DSC-spikes were found at decreasing temperatures. Several K-doped materials decomposed 
during irradiation, i.e. below $100^{\circ} \mathrm{C}$. In order to avoid weight losses during the DSC experiments due to lost fragments, which were blown away by the explosive decomposition, the samples were placed in a closed $\mathrm{Al}$ pan. The pan has a very small hole to allow the eventual release of $\mathrm{Cl}_{2}$ gas. After taking these precautions we did not loose any mass, showing that no significant amounts of $\mathrm{Cl}_{2}$ gas were released and that the voids do not contain significant amounts of $\mathrm{Cl}_{2}$ gas. If we combine these findings with the observed spike-induced decrease of the melting peak of $\mathrm{Na}$, we can conclude unambiguously that during the first short spike up to $30 \%$ of the colloidal $\mathrm{Na}$ reacts with $\mathrm{Cl}_{2}$.

Obviously, the above mentioned results are not in agreement with the alternative proposition for the observed radiation induced decompositions, in which it is assumed that decomposition is due to the expansion of $\mathrm{Cl}_{2}$-gas in radiation induced bubbles. Our observations show that the characteristic feature of the decomposition process is that the amount of radiation induced $\mathrm{Na}$-metal decreases to some extent (up to $30 \%$ in only the first spike). Weight losses are definitely not characteristic for the explosive phenomena in our heavily irradiated samples. As mentioned above, we conclude that the majority of the radiolytic chlorine molecules are not located in the voids. We have several arguments to support this conclusion. First, if significant amounts of chlorine were present in voids, we would expect appreciable weight losses due to the release of gas during the decomposition. On the other hand, we have obtained evidence that the chlorine precipitates are very small, because for many samples we have observed, like for ultra small $\mathrm{Na}$-colloids, more than one $\mathrm{Cl}_{2}$ melting peak. If radiolytic chlorine is not located in the voids, it should be stored somewhere else in the sample, probably as nanobubbles. Finally, we emphasize that the fact that we have observed spike-induced back reactions of $\mathrm{Na}$ and $\mathrm{Cl}_{2}$, also supports the point of view that radiolytic $\mathrm{Na}$ and chlorine is distributed in the $\mathrm{NaCl}$ lattice as extremely small precipitates. If one of the elements $\left(\mathrm{Na}\right.$ or $\left.\mathrm{Cl}_{2}\right)$ is present as large precipitates with sizes of $0.1-1 \mu \mathrm{m}$ the average distance between the products, which feed the spike-induced back reaction, is too large. Even if we assume that about $10 \%$ of the $\mathrm{NaCl}$ lattice is transformed into $\mathrm{Na}$ and $\mathrm{Cl}_{2}$, the distance between the precipitates is typically 0.1-1 $\mu \mathrm{m}$. If on the other hand we assume that the $\mathrm{Na}$ and $\mathrm{Cl}_{2}$ precipitates are both nanometer size objects, the distance between these objects is of the order of $1 \mathrm{~nm}$. This implies that the precipitates are only 
a few lattice distances apart and it is easy to explain shock-induced back reactions in these materials.

Just as stated by Phillips et al. [16], we think that also in heavily irradiated $\mathrm{NaCl}$ voids are the regions of the initial reactions leading to detonation and that the void distribution in the lattice is an important factor controlling the sensitivity to shock and the character of the subsequent detonation front development. Clearly, explosive decomposition differs from smooth, and thermally stimulated back reactions. We assume that shock waves in heavily damaged $\mathrm{NaCl}$ induce very localized, and coherent back reactions between radiation induced $\mathrm{Na}$ and $\mathrm{Cl}_{2}$ precipitates, exactly at the moment when the shock wave passes the region with these precipitates. The energy released by this back reaction is added to the shock wave instantaneously, which leads to amplification of the strength of the shock wave. The shock wave, initiated by a hot spot resulting from a large void, travels in the heavily irradiated crystal and the reaction energy is added very locally to the shock wave. The amplitude of the shock wave increases until the sample decomposes. We assume that in our samples (with sizes $3 * 3 * 1 \mathrm{~mm}^{3}$ ) decomposition takes place after the shock wave has affected $10-30 \%$ of the crystal volume. Only in this way we can understand how it is possible that just one very short thermal spike is capable to wipe out $30 \%$ of the $\mathrm{Na}$ and chlorine precipitates in irradiated $\mathrm{NaCl}$ without any weight loss. After decomposition the shock wave stops and no more chemical energy is released. If the temperature of the sample is increased further, a second hot spot may be created and more chemical energy is released within the fragments, which were more or less unaffected by the first explosion, etc. Indeed, we have observed experimentally in many heavily irradiated samples a multitude of thermal spikes. Finally, after many spikes occurred, the crystal is transformed into a collection of very fine dust-like fragments. Our experimental observations show that these fragments still contain about $50 \%$ of the original amount of stored energy, which was present immediately after the irradiation run.

An interesting observation is that the amount of $\mathrm{Na}$ and $\mathrm{Cl}_{2}$ depends on the dose, the irradiation temperature and the dopant. A similar remark can be made for radiation induced voids, but the development of voids does not scale with the production of $\mathrm{Na}$ and chlorine precipitates. In some samples with large amounts of $\mathrm{Na}$ and $\mathrm{Cl}_{2}$ we did not find extensive void formation. Oppositely, we have observed in some 
materials extensive void formation, while the concentrations of $\mathrm{Na}$ and $\mathrm{Cl}_{2}$ were relatively low. Large voids were found in $\mathrm{NaCl}: \mathrm{K}$ and $\mathrm{NaCl}: \mathrm{Ba}$, while large amounts of $\mathrm{Na}$ and $\mathrm{Cl}_{2}$ were found in $\mathrm{NaCl}$ : $\mathrm{KBF}_{4}$. As mentioned earlier, samples with large voids are unstable, i.e. heavily irradiated samples of $\mathrm{NaCl}: \mathrm{K}$ and $\mathrm{NaCl}: \mathrm{Ba}$ are unstable and were found to explode at low temperatures. The results for $\mathrm{NaCl}: \mathrm{Ba}$ are remarkable, because this material is unstable although the SE peak in heavily irradiated $\mathrm{NaCl}$ : Ba samples is rather small, showing that apart from the $\mathrm{SE}$ due to the back reactions between $\mathrm{Na}$ and $\mathrm{Cl}_{2}$, there is additional SE associated with voids. On the other hand, we note that although the $\mathrm{SE}$ in $\mathrm{NaCl}: \mathrm{KBF}_{4}$ is very large, these samples are relatively stable, which is in accordance with the observation of small void sizes. These experimental facts indicate that the size of the voids and the concentration of $\mathrm{Na}$ and $\mathrm{Cl}_{2}$ are not coupled very strongly. For some samples, however, there should be a considerable amount of SE associated with the voids. In early stages the voids are round, small and distributed more or less randomly over the sample. With increasing size, the voids become elongated and are aligned along the crystallographic $\langle 100\rangle$ axes, showing that some kind of void ordering takes place. This type of ordering has been found for $\mathrm{NaCl}: \mathrm{Ba}$, which, as mentioned above, shows explosive effects for low concentrations of $\mathrm{Na}$ and $\mathrm{Cl}_{2}$ precipitates. In irradiated $\mathrm{NaCl}: \mathrm{Ba}$ crystals long and highly elongated voids have been observed.

In general, it is assumed that in explosives voids are more effective in feeding energy to the shock wave than chemical reactions [17], because the collapse of voids is obviously a fast and instantaneous process. In heavily irradiated $\mathrm{NaCl}$ crystals back reactions between radiation induced $\mathrm{Na}$ and chlorine give rise to significant contributions to the explosive energy. This can be concluded from the experimental results presented in Fig. 6 and the discussion devoted to these results. We have found evidence, that contributions from the instantaneous chemical reactions to the explosive decomposition are associated with the unusual geometrical properties of the $\mathrm{Na}$ and chlorine precipitates. In samples with $5-15 \mathrm{~mol} \% \mathrm{Na}$ the individual $\mathrm{Na}$-colloids are extremely small $(1-2 \mathrm{~nm})$. This has been deduced from the properties of the melting peaks, which show remarkable size effects [18]. The melting peak of $\mathrm{Na}$ is located between 82 and $140^{\circ} \mathrm{C}$, depending on the purity of the samples and the irradiation conditions, such as the 
irradiation temperature, the dose and dose rate. For heavily irradiated samples the position of the melting peak deviates strongly from the one observed for bulk $\mathrm{Na}$. In addition, the melting behavior is affected quite drastically by annealing at low temperatures (e.g. $180^{\circ} \mathrm{C}$ ), while in some cases we have observed changes in the melting parameters of colloidal $\mathrm{Na}$ during annealing at room temperature [19]. These unusual observations can be explained by assuming that the individual precipitates are extremely small and located at very close distances from each other $[18,19]$. In samples with $5-15 \mathrm{~mol} \% \mathrm{Na}$ and $\mathrm{Cl}_{2}$, the average distance between the precipitates is estimated to be about $1 \mathrm{~nm}$. A shock wave, initiated at a void, leads to very high local temperatures and large displacements, which are sufficient to initiate instantaneous and localized back reactions between $\mathrm{Na}$ and $\mathrm{Cl}_{2}$. The corresponding reaction rates are not governed by diffusion processes, but take place instantaneously like for unstable voids, and the corresponding chemical back reactions are therefore assumed to contribute effectively to the strength of the shock wave.

It is worthwhile to investigate stable solids in general to establish if the observations for $\mathrm{NaCl}$ are unique. Explosions of irradiated insulators have not been observed before, probably because (i) sufficiently high damage levels can be obtained only at very high doses, and (ii) the efficiency of the radiolysis process depends sensitively on the presence of dopants and the irradiation temperature [20]. The explosions in $\mathrm{NaCl}$ can be explained by the features of the damage centers. Samples with large voids are unstable, and these voids undoubtably play a central role in the initiation processes. Nanometer sized $\mathrm{Na}$ and $\mathrm{Cl}_{2}$ precipitates are important reaction products, giving rise to very fast and local back reactions, an efficient transfer of chemical energy to the shock wave and ultimately, explosive decomposition.

\section{SUMMARY}

In this paper we have shown that explosive decomposition of stable solids may take place as a result of heavy irradiation. Convincing evidence has been obtained by carrying out combined latent heat (DSC), SEM and weight measurements before and after decomposition took place. These experiments have shown that during very short thermal 
spikes up to $30 \%$ of the Na-colloids and chlorine precipitates in the heavily irradiated samples was involved in instantaneous back reactions of the type $2 \mathrm{Na}+\mathrm{Cl}_{2} \rightarrow 2 \mathrm{NaCl}$.

It appeared that voids play an important role in the initiation of the explosive decomposition of irradiated $\mathrm{NaCl}$. Samples with large numbers of large voids decompose at relatively low temperatures. The presence of these voids depends on the doping of the $\mathrm{NaCl}$ samples. Materials with $\mathrm{K}$ and $\mathrm{Ba}$ impurities were found to decompose rather easily, whereas nominally pure $\mathrm{NaCl}$ and samples with $\mathrm{KBF}_{4}$ explode only after exposure to extremely high doses of irradiation or heating to rather high temperatures.

\section{References}

[1] C.L. Mader, Numerical modeling of detonations, Los Alamos Series in Basic and Applied Sciences, University of California Press (1979).

[2] D.H. Tsai, J. Chem. Phys. 95, 7497-7503 (1991).

[3] R. Belmas and J.-P. Plotard, Journal de Physique IV Colloque C4, Suppl. au J. de Physique III, 5, 61-87 (1995).

[4] A.W. Campbell, W.C. Davies, J.B. Ramsay and J.R. Travis, Phys, of Fluids (USA), 4(4), 511-521 (1961).

[5] F.P. Bowden and A.D. Yoffe, Fast Reactions in Solids, Butterworths Scientific Publications, London (1958).

[6] M.H. Miles, K.L. DeVries, A.D. Britt and W.B. Moniz, Propellants, Explos., Pyrotech. 8, 49-52 (1983).

[7] E.L. Lee and C.M. Tarver, Phys. Fluids, 23, 2362 (1980).

[8] V.I. Dubinko, A.A. Turkin, D.I. Vainshtein and H.W. den Hartog, accepted for publication in Radiation Eff. and Def. in Sol.

[9] B.A. Khasainov, A.A. Borisov and B.S. Ermolayev, Shock wave predetonation processes in porous high explosives, reported at the $8 t h$ ICOGER, Minsk, USSR, Aug. 23-26, 1981.

[10] L.B. Seely, Proc. of the Fourth Electric Initiator Symposium (Franklin Institute, Philadelphia, Pa. 1963), paper 27.

[11] R.H. Stresau and J.E. Kennedy, Sixth Symposium (International) on Detonation, ACR-184 (Office of Naval Research, Pasadena, Calif., 1970), p. 219.

[12] J. Wackerle, J.O. Johnson and P.M. Halleck, Sixth Symposium (International) on Detonation, ACR-221 (Office of Naval Research, Coronado, Calif. 1976), p. 20.

[13] J. Wackerle, R.L. Rabie, M.J. Ginsberg and A.B. Anderson, Proc. of the Symposium on High Dynamic Pressures (Commissariat a l'Energie Atomique Paris, France, 1978), p. 127.

[14] J.W. Mintmire, D.H. Robertson and C.T. White, Phys. Rev. B 49, 14859 (1994).

[15] L. Phillips and E.S. Oran, Shock Compression of Condensed Matter 1991, Eds. S.C. Schmidt, R.D. Dick, J.W. Forbes and D.G. Tasker, Elsevier Science Publishers B.V. (1992).

[16] L. Phillips, R.S. Sinkovits, E.S. Oran and J.P. Boris, J. Phys.: Condensed Matter 5, 6357 (1993).

[17] L. Phillips, J. Phys.: Condensed Matter 7, 7813 (1995). 
[18] J. Seinen, J.R.W. Weerkamp, J.C. Groote and H.W. den Hartog, Phys. Rev. B 50, 9793 (1994).

[19] J. Seinen, D.I. Vainshtein, H.C. Datema and H.W. den Hartog, J. Phys.: Condensed Matter 7, 705 (1995).

[20] H.W. den Hartog, J.C. Groote and J.R.W. Weerkamp, Rad. Effects and Defects in Solids 139, 1-19 (1996). 